\title{
Colloids Produced by Simple Self-Assembly of Inorganic Tennis Balls and Nonrigid Polypyridyl Ligands
}

\author{
Kyungeun Oh, Hanyoung Lee, Ki-Hyun Kim, Youn Sang Kim, Wonwoo Nam, and Kwan Mook Kim* \\ Bio-Chiral Lab, Division of Nano Sciences,Ewha Womans University, Seoul 120-750, Korea. "E-mail: khnook@ewha.ac.kr \\ Received Angust 9, 2007
}

Key Words : Inorganic tennis ball, Colloid, Ilexagonal particle, Coordination polymer

Inorganic Tennis Balls (ITBs) are supramolecules produced by self-assembly of dithioylidenemalonato-platinum(II) complexes and simple metal salts. ${ }^{1-3}$ The copper-based ITB, $\left[\left[[(d a c h) \operatorname{Pt}(d t e v m)]_{2} \mathrm{Cu}\right]_{2}\right] \cdot(\mathrm{OTf})_{4}$ (where dach $=\operatorname{trans}( \pm)-$ 1,2-diaminocyclohexane and dtevm = 1,3-dithiepane-2ylidenemalonate) has been reported to possess two metalcentered hydrophobic pockets in its surface and generate an 1 -D coordination polymer by the self-assembly with 4,4 'bipyridine (BPY). ${ }^{2}$ In this context, we were interested in the self assembly of ITBs and nonrigid ligands, bis-(4-pyridylmethyl-amine (BPMA) and tris-(4-pyridylmethyl)-amine (TPMA).<smiles>c1cc(CNCc2ccncc2)ccn1</smiles>

BPMA

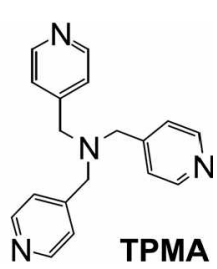

TPMA
Nonrigid polypyridyl ligands have been seldom used as bridging units of coordination polymers, ${ }^{4}$ probably due to their tendency to generate unpredictable polymeric structures. Here we report the colloids obtained by the selfassembly of ITBs and nonrigid polypyridyl compounds, BPMA and TPMA. Colloids made of coordination polymers have recently been of interest since they are inorganicorganic hybrid materials promising some advantageous properties and obtainable by simple procedure of mixing.

The bridging ligand, BPMA, could be prepared by literature method. ${ }^{9}$ Another bridging ligand, TPMA, was synthesized by the reaction of 4-pyridinecarboxaldehyde and 4-aminomethylpyridine in 2:1 ratio in the presence of sodium triacetoxyborohydride and acetic acid in THF followed by column chromatography with EA and methanol (95:5). The chemical structure of the compound was confirmed by ${ }^{\prime} H$ NMR and ESI-MS. ${ }^{10}$

The coordination of a pyridyl nitrogen of BPMA to a cobalt(II) ion in the ITB, [[[(dach) Pt $\left.\left.(d t e v m)]_{2} \mathrm{Co}\right]_{2}\left(\mathrm{NO}_{3}^{-}\right)\right]$ $\cdot\left(\mathrm{NO}_{3}{ }^{-}\right)_{3}$, was confirmed by X-ray crystallographic study." Brown block crystals were grown from the methanol solution of the ITB and BPMA with more than $80 \%$ yield. The crystal has 1-D coordination polymeric structure as shown in Figure 1. One BPMA molecule bridges two ITBs through coordination of a pyridyl nitrogen to a cobalt(II) ion at the surface of the ITB. The distance between cobalt(II) ion and pyridyl nitrogen is $2.165(16) \AA$. The orientation of an ITB in (a)

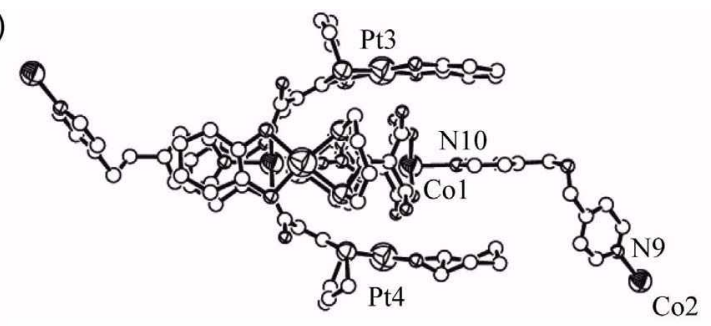

(b)

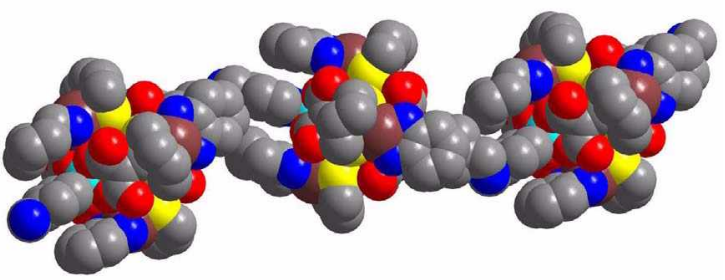

Figure 1. (a) Molecular structure showing the coordination of a pyridyl nitrogen of BPM $A$ to a cobalt(II) ion in the ITB, [[[(dach)Pt $\left.\left.(\text { dieym) }]_{2} \mathrm{Co}\right]_{2}\left(\mathrm{NO}_{3}^{-}\right)\right] \cdot\left(\mathrm{NO}_{3}^{-}\right)_{3}$. (b) Space filling diagram: a cobalt in green, a nitrogen in blue, an oxygen in red, a carbon in grey and a sulphur in yellow.

$\mathbf{1}$ is twisted against the neighboring ITBs due to the bented nature of BPMA, producing a zigzag type coordination polymer.

It is interesting that a colloidal solution is immediately formed when BPMA is added to an ethanol solution of the ITB, [[[(dach) Pt(dteym) $\left.\left.]_{2} \mathrm{Ni}\right]_{2}\left(\mathrm{ClO}_{4}^{-}\right)\right] \cdot\left(\mathrm{ClO}_{4}^{-}\right)_{3}$. Figure 2 shows the SEM image of the particles isolated after $24 \mathrm{~h}$ standing by centrifugation from the colloidal solution obtained by the addition of BPMA to $5 \mathrm{mM}$ solution of the ITB at room temperature. The yield of isolated particles was around $50-80 \%$. The particles are in good spherical shapes with diameter in the range of $400-600 \mathrm{~nm}$ (Figure 2). Size distribution of the colloidal solution demonstrates gaussian shapes and is in good agreement with the SEM result. The particles are highly soluble in water and polar solvents such as DMF and DMSO. Integration of the peaks appeared in the 'H NMR in DMSO- $d_{6}$ supports the presence in 1:1 ratio of BPMA and ITB in the particles. The size tends to increase with prolonged standing of the colloidal solutions but does not change significantly depending on the conditions such as concentrations of the reactants, addition rates, stiming speeds, temperatures and ratios of the reactants.

The colloidal solution obtained by the addition of TPMA to an ethanol solution of $\left[\left[[(d a c h) \mathrm{Pt}(d t e v m)]_{2} \mathrm{Co}\right]_{2}\left(\mathrm{NO}_{3}{ }^{-}\right)\right]$ $\cdot\left(\mathrm{NO}_{3}{ }^{-}\right)_{3}$ showed different features; the solution glittered 
(a)

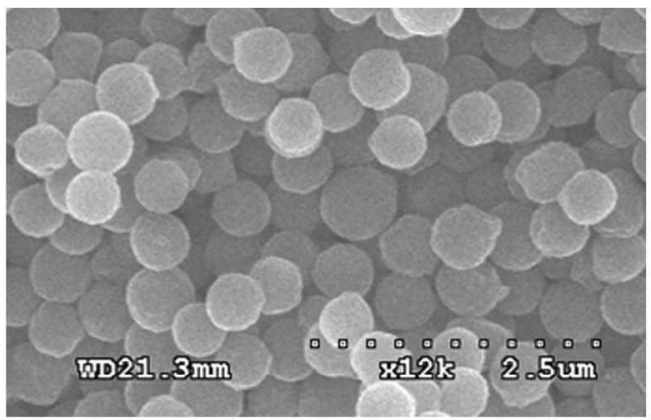

(b)

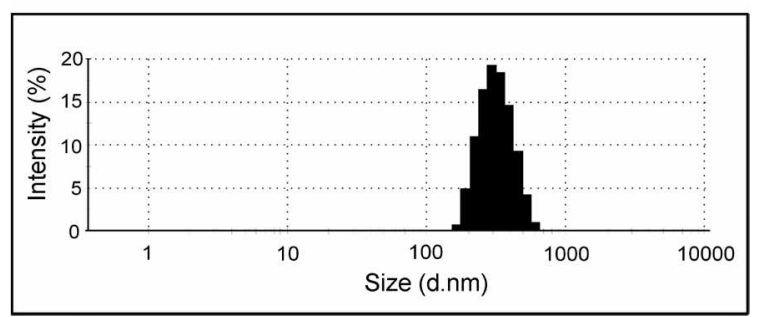

Figure 2. (a) SEM image of the spherical colloidal particles obtained from the self-assembly of $\left[i\left[i_{4}(\mathrm{c} / \mathrm{ch}) \mathrm{P}(\mathrm{d}(\mathrm{dey})]_{2} \mathrm{Ni}\right]_{2}\left(\mathrm{ClO}_{4}^{-}\right)\right]$ $\cdot\left(\mathrm{ClO}_{4}^{-}\right)_{3}$ and BPMA. (b) Size distribution by the intensity of laserlight scattering.

(a)

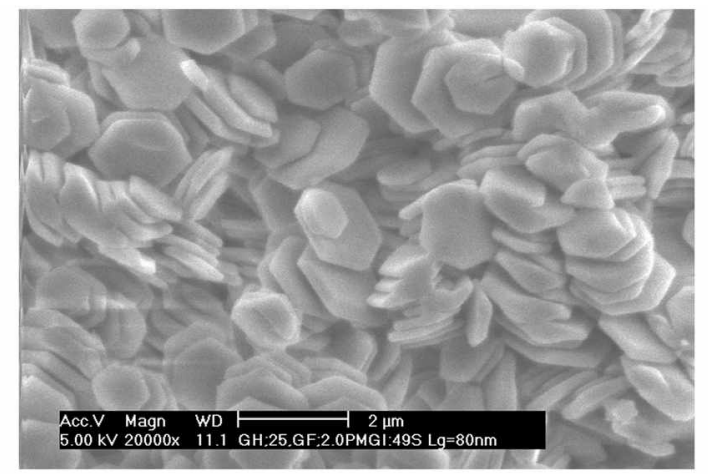

(b)

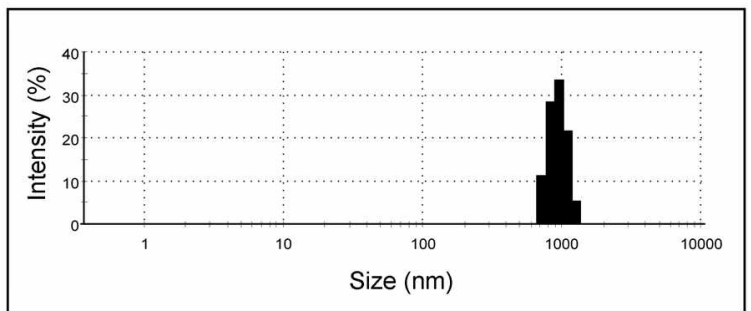

Figure 3. (a) SEM inage of the colloidal hexagonal plates obtaincd from the self-assembly of TPMA and $\left[\left[[(\text { dach }) \mathrm{Pt}(\text { dteym })]_{2} \mathrm{Co}\right]_{2}-\right.$ $\left.\left(\mathrm{NO}_{3}{ }^{-}\right)\right] \cdot\left(\mathrm{NO}_{3}^{-}\right)_{3}$. (b) Size distribution by the intensity of laser-light scattering.

upon light, indicating that the colloidal particles have crystallinity. The yield of isolated particles was $\rightarrow 70 \%$. The particles were highly soluble in water and polar organic solvent such as DMF and DMSO. The inclusion of TPMA ligand in the particles could be confirmed by 'H NMR in DMSO-d $d_{6}$. Integration of the peaks appeared in the NMR supports 1:1 ratio of TPMA and ITB in the particles. SEM image of the particles are shown in Figure 3. The particles are in shapes of hexagonal plates whose size is $1-2 \mu \mathrm{m}$ in wideness and $50 \mathrm{~nm}$ in thickness.
Particles of hexagonal plate type were also obtained from the colloidal solution formed by the nickel(II) based ITB, $\left[\left[[(\text { dach }) \mathrm{Pt}(\text { dteym })]_{2} \mathrm{Ni}_{2}\right]_{2}\left(\mathrm{NO}_{3}{ }^{-}\right)\right] \cdot\left(\mathrm{NO}_{3}^{-}\right)_{3}$, and TPMA in ethanol (Supporting Information). It is a curious result that hexagonal particles are formed from ITBs with $\mathrm{NO}_{3}{ }^{-}$anion but not from ITBs with $\mathrm{ClO}_{4}^{-}$anion.

In summary, colloidal solutions with hexgonal and spherical particles have been obtained from the simple selfassembly of ITBs and non-rigid polypyridyl ligands. Coordination of BPMA pyridyl nitrogen was confirmed by X-ray crystallography. It is a very rare case that the colloidal solution with particles of hexagonal plate is obtained from the coordination-polymer-based self-assembly. The particles in this study potentially can be used as decomposable colloidal templates for the fabrication of hollow species because they are well soluble in water and DMF. ${ }^{12-14}$

Acknowledgements. This research was supported by the Ministry of Science and Technology of Korea through NRL and SRC program of MOST/KOSEF at Ewha Womans University (grant: R11-2005-008-000000) and by the Korea Research Foundation Grant (KRF-2004-005-C00093).

Supporting Information: X-ray crystallographic data for the I-D coordination polymer in cif format and SEM images of other colloids are available at bkcs website (www.kcsnet. or.kr/bkcs).

\section{References}

1. Kim, K. M.; Park, J. S.; Kim, Y.-S.; Jun. Y. J.; Jun, Y. J.; Kang, T. Y.; Son, Y. S.; Jun M.-J. Angew: Chent. Int. Ed. Engl. 2001, 40,2458.

2. Kim, K.H.; Song, R, Kim, K. M. J, Am, Chem. Soc, 2003, 125, 7170.

3. Park, J. S.; Park, T.-J.; Kim, K.-H.; Oh, K.; Seo, M.-S.; Lee, H.-I.; Jun, M.-Li: Nam, W.; Kim, K. M, Bull. Korean Chem. Soc, 2006, $27,193$.

4. (a) Holliday, B. J.; Mirkin, C. A. Angew: Chen. Imt Ed. 2001, 40, 2022. (b) Seidel, S. R.; Stang, P. J. Acc. Chem. Res. 2002, 35, 972. (c) Thompson, L. K. Coord. Chem. Rev, 2002, 233 , 193. (d) James, S. L. Chem. Soc. Rev, 2003, 32, 276. (e) Cha, M. S.; Kim, S. A.; Yoo, K. H.; Park, K.-M.; Jung, O.-S. Bull. Korean Chem. Soc. 2006, 27, 137. (f) Kim, H. N.; Lee, H. K.; Lee, S. W. Bull. Korean Chem. Soc. 2005, 26, 892 .

5. Sun, X.; Dong, S.; Wang, E. J. Am. Chem. Soc. 2005, $/ 27,13102$.

6. Oh, M.; Mirkin, C. A. Nantre 2005, 438, 651,

7. Oh, M.; Mirkin, C. A. Angew: Chem. Int, Ed, 2006, 45, 5492.

8. Yamada, M.; Arai, M.; Kurihara, M.; Sakamolo, M.; Miyake, M. J. Ant. Chem. Soc. 2004, 126, 9482.

9. Kostka-Trabka, E.; Ocetkiewicz, A.; Swies, J.; Durek, B.; Gryglewski, R. J. Diss. Pharm. Pharn. 1969.21.93.

10. 'H-NMR (CDCl $\left.l_{7,}, p p m\right)$ of TPMA: $8.51(6 \mathrm{H}, d), 7.35(6 \mathrm{H}, d)$, $3.66(6 \mathrm{H}, s), m, p .7 \mathrm{I}{ }^{\circ} \mathrm{C}$.

11. The X-ray data were collected using SMART APEX CCD systems equipped with a Mo X-ray tube at the ambient temperature. Crystal data of 1: orthorhombic, Pccn (No. 56), $Z=8, a=$ $35.7296(24) \AA, b=24.3704(16) \AA$, and $c=2.3606(18) \AA . V=$ $22083(3) \AA^{3}, \mu=5.564 \mathrm{~mm}^{-1}, d_{\mathrm{csk}}=1.665 \mathrm{~g} / \mathrm{cm}^{3}, \mathrm{RI}=7.89, \mathrm{wR} 2$ $=21.38 \%$ for 7444 unique reflections, 1122 variables and 147 restraints. The structure solution and refinement of the data were handled using the SHELXS-86 and SHELXL-97 programs.

12. Caruso, F.; Caruso, R. A.; Mohwald, H. Science 1998, 282, 1111.

13. Yang, Z.; Niu, Z.; Lu, Y.; Hu, Z.; Han, C. C. Angew. Chen. Int. Ed, 2003, 42, 1943.

14. Yang, R.; Li, H.; Qiu, X.; Chen, L. Chem,-A Em:J. 2006, $12,4083$. 